\section{Additional treatment of recurrent or regrowing cystic thyroid nodules after ethanol ablation}

\author{
Jung Suk Sim
}

Department of Radiology, Withsim Clinic, Seongnam, Korea

I read with great interest the study by Yim et al. entitled "Recurrence and additional treatment of cystic thyroid nodules after ethanol ablation: validation of three proposed criteria" [1]. Their paper was well-written, and I have no major objections to any of the points that the authors made. Nevertheless, I would like to ask a few questions and share my thoughts.

The conclusion contains a significant sentence: "The decision of whether to perform additional treatment after EA for cystic or predominantly cystic thyroid nodules should be carefully made using a combination of patients' actual clinical problems and US features." However, it would be better if more specific information were to be provided. For example, a solid component with vascularity was found with a high frequency (9 of 19) in the failure group. If the definition of recurrence as "demonstration of a solid component with vascularity" was applied, avoidable additional ethanol ablation might be performed in 35 of 45 cases. With this in mind, were there any impressions not described in the paper that informed the decision of whether to perform additional treatment if a solid component with vascularity was found at the 1-month follow-up? If so, please share any relevant information. On a more general note, after completing this study, in what cases do you think should additional treatment be performed?

An improvement in clinical symptoms may also be an important criterion for determining success and/or failure and for choosing whether to perform additional treatment. Do the authors think it is better to follow-up the patient than to provide additional treatment if the symptoms improve, even if the 1-month volume reduction ratio (VRR) is less than $50 \%$ ? For reference, in thermal ablation, the VRR is a common criterion for therapeutic success after 1 year, not 1 month. A VRR of less than $50 \%$ after 1 year is a risk factor for regrowth [2]; thus, it may be better to perform additional ablation even with symptom improvement.

Finally, I would like to give my opinion on the term "recurrence." Both ethanol ablation and thermal ablation are ablation therapies for thyroid nodules. Therefore, I think a consistent definition should be applied to these commonly used terms. Regrowth may be defined as the volume increasing by more than $50 \%$ compared with the smallest volume recorded after ablation $[3,4]$. Although the term "recurrence" is mainly used in a similar context to that of regrowth, the definition of recurrence is vaguer. Nevertheless, both regrowth and recurrence seem to be frequently used to describe reversal of the therapeutic effect. In this paper, as well as the studies of Suh et al. [5] and Bennedbaek and Hegedus [6], the term "recurrence" is used to suggest the failure of treatment or insufficient volume reduction; thus, this meaning is distinct from the general meaning of the term. Del Prete et al. [7] used the term "unsuccessful" to indicate a VRR $<50 \%$. Moreover, the term "recurrence" is used when the volume increases by more than 10\% after treatment [7]. Zingrillo et al. [8] describes a VRR $<50 \%$ as a failure to reduce nodule volume significantly. I would like to ask the authors to clarify

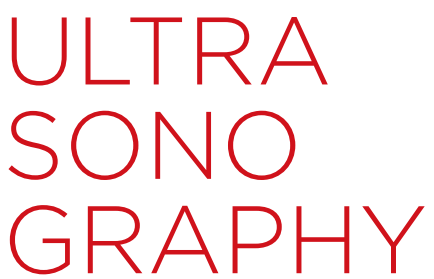

\section{LETTER}

https://doi.org/10.14366/usg.21007 pISSN: 2288-5919・elSSN: 2288-5943 Ultrasonography 2021;40:617-618

Received: January 12, 2021

Revised: January 12, 2021

Accepted: February 14, 2021

Correspondence to: Jung Suk Sim, MD, PhD, Department of Radiology, Withsim Clinic, 353 Hwangsaeul-ro, Bundang-gu, Seongnam 13590, Korea

Tel. +82-31-708-3444

Fax. +82-31-704-8179

E-mail: jungsuk.sim@gmail.com

This is an Open Access article distributed under the terms of the Creative Commons Attribution NonCommercial License (http://creativecommons.org/ licenses/by-nc/4.0/) which permits unrestricted noncommercial use, distribution, and reproduction in any medium, provided the original work is properly cited.

Copyright @ 2021 Korean Society of Ultrasound in Medicine (KSUM)

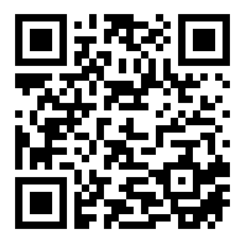

How to cite this article:

Sim JS. Additional treatment of recurrent or regrowing cystic thyroid nodules after ethanol ablation. Ultrasonography. 2021 0ct;40(4):617-618. 
what they think would be appropriate definitions of regrowth, recurrence, and therapeutic success and failure.

In conclusion, this paper covers an exciting topic and is of great clinical value. However, it would be very helpful to provide more specific information so that readers can apply it directly to clinical practice. In addition, I would like to request your valuable opinion on terminological consistency related to recurrence.

ORCID: Jung Suk Sim: https://orcid.org/0000-0001-6803-3544

\section{Conflict of Interest}

No potential conflict of interest relevant to this article was reported.

\section{References}

1. Yim Y, Baek JH, Chung SR, Choi YJ, Lee JH. Recurrence and additional treatment of cystic thyroid nodules after ethanol ablation: validation of three proposed criteria. Ultrasonography 2021;40:378-386.

2. Negro R, Greco G, Deandrea M, Rucco M, Trimboli P. Twelve-month volume reduction ratio predicts regrowth and time to regrowth in thyroid nodules submitted to laser ablation: a 5-year follow-up retrospective study. Korean J Radiol 2020;21:764-772.

3. Sim JS, Baek JH, Lee J, Cho W, Jung SI. Radiofrequency ablation of benign thyroid nodules: depicting early sign of regrowth by calculating vital volume. Int J Hyperthermia 2017;33:905-910.

4. Mauri G, Pacella CM, Papini E, Solbiati L, Goldberg SN, Ahmed M, et al. Image-guided thyroid ablation: proposal for standardization of terminology and reporting criteria. Thyroid 2019;29:611-618.

5. Suh CH, Baek JH, Ha EJ, Choi YJ, Lee JH, Kim JK, et al. Ethanol ablation of predominantly cystic thyroid nodules: evaluation of recurrence rate and factors related to recurrence. Clin Radiol 2015;70:42-47.

6. Bennedbaek FN, Hegedus L. Treatment of recurrent thyroid cysts with ethanol: a randomized double-blind controlled trial. J Clin Endocrinol Metab 2003;88:5773-5777.

7. Del Prete S, Caraglia M, Russo D, Vitale G, Giuberti G, Marra M, et al. Percutaneous ethanol injection efficacy in the treatment of large symptomatic thyroid cystic nodules: ten-year follow-up of a large series. Thyroid 2002;12:815-821.

8. Zingrillo $M$, Torlontano $M$, Chiarella R, Ghiggi MR, Nirchio V, Bisceglia $M$, et al. Percutaneous ethanol injection may be a definitive treatment for symptomatic thyroid cystic nodules not treatable by surgery: five-year follow-up study. Thyroid 1999;9:763767. 